\title{
Stock Options as Barrier Contingent Claims
}

\author{
Jan Ericsson*\& Joel Reneby ${ }^{\dagger}$
}

May 2000

SSE/EFI Working Paper Series in Economics and Finance No. 137

\begin{abstract}
We suggest a comprehensive model that values securities as options and consequently ordinary stock options as compound options. Extending the basic Black-Scholes model, we can incorporate common contractual features and stylized facts.

More specifically, we derive a closed form solution for the price of a call option on a down-and-out call. We then show how the obtained result can be generalized in order to price options on complex corporate securities, allowing among other things for corporate taxation, costly financial distress and deviations from the absolute priority rule. The characteristics of the model are illustrated with numerical examples.
\end{abstract}

\footnotetext{
*Faculty of Management, McGill University, 1001 Sherbrooke Street West, Montreal, Quebec, Canada H3A 1G5. Tel. +1 514 398-3186, Fax +1 514 398-3186. Email: jan.ericsson@mcgill.ca

†Department of Finance, Stockholm School of Economics, Box 6501, S-113 83 Stockholm, Sweden. Tel: +46 8736 9143, fax +468312327. E-mail: joel.reneby@hhs.se

$\ddagger$ Please note that this version replaces an earlier incomplete draft mistakenly made available on the internet. We apologize for any inconvenience. This is the original May 2000 version, following Reneby (1998).
} 


\section{Introduction}

Contingent claims analysis has frequently been used to price corporate securities and related derivatives. The idea is that securities can be valued as options and that consequently ordinary (stock) options are valued as compound options. Only when the models extend the basic Black \& Scholes framework, however, do the pricing formulae for the corporate securities generate prices in line with actual ones. Yet no such model also incorporating derivatives in a general way has been developed.

We suggest a comprehensive model which allows us to incorporate common contractual features and stylized facts. More specifically, we derive a closed form solution for the price of a call option on a down-and-out call. We then show how the obtained result can be generalized in order to price options on complex corporate securities, allowing among other things for corporate taxation, costly financial distress and deviations from the absolute priority rule. The characteristics of the model are illustrated with numerical examples.

Black \& Scholes (1973) suggest for the first time that corporate securities can be viewed as options on the underlying firm value and Merton (1974) provides an application of these ideas to the pricing of corporate debt. The same insight is exploited by Geske (1979) who takes a step further in pricing stock options as compound options on the firm's asset value. In doing, so the stock volatility becomes an endogenous stochastic process dependent on firm leverage, relaxing the empirically refuted assumption of constant stock return volatility.

A shortcoming of early models is that financial distress only can occur at maturity of debt. Kim et al. (1993) show that Merton's 1974 model is unable to generate credit spreads in line with levels observed in practice. Hence, the corresponding equity prices and thus also option prices are likely to be biased. Black \& Cox (1976) allow for financial distress prior to the maturity of debt by modelling default as taking place when the value of the firm's assets hits a lower boundary. ${ }^{1}$ However, they value only corporate securities and do not address the pricing of options. Toft \& Prucyk (1997), on the other hand, do

\footnotetext{
${ }^{1}$ Other models that have since employed this approach of modelling financial distress are Nielsen et al. (1993), Kim et al. (1993), Leland (1994), Leland \& Toft (1996) and Longstaff \& Schwartz (1995).

The pricing of barrier options was pioneered by Merton (1973) and has since been treated in a multitude of papers including Björk (1994), Rich (1994) and Carr (1995).
} 
value stock options in a firm value based model but restrict their analysis to a class of capital structures with perpetual debt.

Ericsson \& Reneby (1998) suggest a simple framework to apply the option approach to the valuation of corporate securities when default is triggered by a barrier in addition to the inability to repay debt at maturity. Claims to the firm's assets with general payoff structures can be priced as portfolios of standard and binary barrier options. In this paper we build on these ideas in order to develop a framework for valuing European options on corporate securities as compound contingent claims when default can occur at a random point in time. It is our view that the framework should, above all, be applied to non-standardized securities such as OTC-derivatives, new debt issues with embedded options and financial guarantees. A new debt issue, for instance, alters the capital structure. Other models, that do not take this into account, will fail to capture the ensuing changes in the volatilities of the firm's securities. Options, being inherently sensitive to volatility changes, thus require a structural model such as ours to be accurately priced in those circumstances.

We view the main contribution of this paper as being twofold. First, we extend Geske's compound option pricing model to encompass an underlying down-and-out call. Second, we provide a general framework in which both underlying corporate securities and derivatives can be valued consistently in an environment where their volatility is driven by changes in leverage.

The paper is organized as follows. Section 2 lays out the modelling environment and the basic assumptions. Section 3 derives the price of a call written on a down-and-out call option. Section 4 generalizes to options on general corporate securities. The section which follows contains some numerical results and section 6 concludes.

\section{Setup}

We make the standard Black \& Scholes assumptions about the economy. The interest rate is constant, trading takes place continuously without transaction costs, unlimited short sales are permitted and arbitrage opportunities are ruled out. The dynamics of the firm's asset value $\omega$ are assumed to be determined by a geometric Brownian motion with expected return $\mu$, payout ratio $\beta$ and 
standard deviation $\sigma$ :

$$
d \omega=(\mu-\beta) \omega d t+\sigma \omega d W
$$

Note that we do not assume that the assets are traded - we only need to assume that some security issued against the assets of the firm, such as equity, is traded (Ericsson \& Reneby (1999) discuss the state variable assumptions for firm value based pricing models in detail).

Default prior to maturity occurs when the value of the firm's assets reaches a lower barrier $L .{ }^{2}$ We take the firm's investment policy to be independent of its financial policy which in this setting implies that the parameters of the asset value process are exogenous constants. Note that this rules out any strategic considerations such as, for example, opportunistic investment policy changes by the management on behalf of shareholders. ${ }^{3}$

The assumption of a constant risk-free interest rate may seem restrictive, in particular if one wishes to value corporate debt and associated options. However, Kim et al. (1993) show that although yields on Treasury and non-callable corporate bonds are sensitive to the modelling of interest rate risk, the spread between the yields on these securities is relatively insensitive to interest rate uncertainty. Thus, in situations where assuming a constant interest rate is clearly inappropriate, our model may be used to price credit risk discounts.

In what follows we value a call option written on a down-and-out call. In section 4 the pricing formula is generalized in order to value options on complex corporate securities in a straightforward manner.

\section{The Compound Barrier Call}

The objective of this section is to price a call option on a down-and-out call. The underlying call matures at $T$ and has exercise price $F$ and the compound call matures at $S<T$ with exercise price $K$. This can be thought of as a call with exercise price $K$ written on equity in a firm that has issued discount debt with face value $F$.

Denote with $C\left(f_{t}, t ; X, S\right)$ the price of a call at time $t$ with exercise price $X$ and maturity at $S$ written on an asset with price $f_{t}$. Using subscript ${ }_{L}$ to denote

\footnotetext{
${ }^{2}$ The barrier can be an exogenous function of debt or determined as the outcome of some endogenous bankruptcy mechanism.

${ }^{3}$ See Ericsson (2000) for a model in which this is not the case. In this paper the volatility parameter $\sigma$ is left to the discretion of the firm's management.
} 
the down-and-out feature with barrier $L$, we can write the price of the compound call as $C\left(C_{L}\left(\omega_{t}, t ; F, T\right), t ; K, S\right)$. Furthermore, let $I_{\{A, B, C, \ldots\}}$ be the indicator function for the events $\{A, B, C, \ldots\}$ and denote with $\tau_{S}$ the first passage time of $\omega$ to $L$ in the interval $\theta_{S}=[t, S]$ and with $\tau_{T}$ the first passage time in the interval $\theta_{T}=(S, T]$. Consequently, the down-and-out feature of a call's payoff can be formalized as $C_{L}\left(\omega_{T}, T ; X, T\right)=C\left(\omega_{T}, T ; X, T\right) \times I_{\left\{\tau_{S} \notin \theta_{S}, \tau_{T} \notin \theta_{T}\right\}}$. From standard theory it follows that we can write the price of the compound call as

$$
C\left(C_{L}\left(\omega_{t}, t ; F, T\right), t ; K, S\right)=e^{-r(S-t)} \cdot E^{B}\left[\left(C_{L}\left(\omega_{S}, S ; F, T\right)-K\right) \cdot I_{\left\{C_{L}>K\right\}}\right]
$$

where $E^{B}$ denotes expectations taken under the pricing measure. The value of the underlying call at maturity of the compound call is given by

$$
C_{L}\left(\omega_{S}, S ; F, T\right)=e^{-r(T-S)} \cdot E_{S}^{B}\left[\left(\omega_{T}-F\right) \cdot I_{\left\{\omega_{T}>F, \tau_{T} \notin \theta_{T}\right\}}\right] \cdot I_{\left\{\tau_{S} \notin \theta_{S}\right\}}
$$

Subscript $S$ denotes expectations conditional on information at time $S$. Inserting, we obtain

$$
\begin{aligned}
& C\left(C_{L}\left(\omega_{t}, t ; F, T\right) ; K, S\right) \\
= & e^{-r(T-t)} \cdot E^{B}\left[\omega_{T} \cdot I_{\left\{\omega_{T}>F, \tau_{T} \notin \theta_{T}, \omega_{S}>\bar{\omega}, \tau_{S} \notin \theta_{S}\right\}}\right] \\
& -e^{-r(T-t)} F \cdot E^{B}\left[I_{\left\{\omega_{T}>F, \tau_{T} \notin \theta_{T}, \omega_{S}>\bar{\omega}, \tau_{S} \notin \theta_{S}\right\}}\right] \\
& -e^{-r(S-t)} K \cdot E^{B}\left[I_{\left\{\omega_{S}>\bar{\omega}, \tau_{S} \notin \theta_{S}\right\}}\right]
\end{aligned}
$$

We define $\bar{\omega}$ as the value of $\omega_{S}$ that solves $C_{L}\left(\omega_{S}, S ; F, T\right)=K$; that is the exercise price in terms of the state variable. ${ }^{4}$ The monotonicity of $C_{L}$ with respect to $\omega$ then implies that the event $\left\{C_{L}>K\right\}$ is equivalent to $\left\{\omega_{S}>\bar{\omega}\right\} \cap$ $\left\{\tau_{S} \notin \theta_{S}\right\}$.

We can separate the two variables within the expectation brackets of the first term on the right hand side of (2) by a change of probability measure. Defining a new measure $Q^{\omega}$, where prices normalized with the asset value process are martingales, ${ }^{5}$ we can rewrite the first term on the RHS of (2) $\mathrm{as}^{6}$

$$
e^{-r(T-t)} \cdot E^{B}\left[\omega_{T}\right] \cdot E^{\omega}\left[I_{\left\{\omega_{T}>F, \tau_{T} \notin \theta_{T}, \omega_{S}>\bar{\omega}, \tau_{S} \notin \theta_{S}\right\}}\right]
$$

For convenience, define the in-the-money events at times $S$ and $T$ as follows:

\footnotetext{
${ }^{4}$ Throughout the analysis, to make it non trivial, we assume $\bar{\omega}, F, \omega_{0}>L$.

${ }^{5}$ Specifically, $e^{\beta(T-t)} \omega_{t}$ is used as numeraire.

${ }^{6}$ See e.g. Geman et al. (1995) or Björk (1994).
} 
Definition 1 Let $A_{T}=\left\{\omega_{T}>F, \tau_{T} \notin \theta_{T}, \omega_{S}>\bar{\omega}, \tau_{S} \notin \theta_{S}\right\}$. The m-probability of its occurence is $Q^{m}\left(A_{T}\right)=E^{m}\left[I_{\left\{A_{T}\right\}}\right]$.

Definition 2 Let $A_{S}=\left\{\omega_{S}>\bar{\omega}, \tau_{S} \notin \theta_{S}\right\}$. The m-probability of its occurence is $Q^{m}\left(A_{S}\right)=E^{m}\left[I_{\left\{A_{S}\right\}}\right]$.

What remains is to find analytic expressions for these probabilities and hence for the price of the compound call. This is done explicitly in appendix B and the result is given in the following lemma:

Lemma 1 The probability of the in-the-money event $A_{T}$ under the probability measures $m=\{B, \omega, G\}$ are given by

$$
\begin{aligned}
& Q^{m}\left(A_{T}\right)=\quad N\left(d_{S}^{m}\left(\frac{\omega_{0}}{\bar{\omega}}\right), d_{T}^{m}\left(\frac{\omega_{0}}{F}\right), \rho\right) \\
& -\left(\frac{L}{\omega_{0}}\right)^{\frac{2}{\sigma} h^{m}} N\left(d_{S}^{m}\left(\frac{L^{2}}{\omega_{0} \cdot \bar{\omega}}\right), d_{T}^{m}\left(\frac{L^{2}}{\omega_{0} \cdot F}\right), \rho\right) \\
& -\left(\frac{L}{\omega_{0}}\right)^{\frac{2}{\sigma} h^{m}} N\left(-d_{S}^{m}\left(\frac{\bar{\omega}}{\omega_{0}}\right), d_{T}^{m}\left(\frac{L^{2}}{\omega_{0} \cdot F}\right),-\rho\right) \\
& +\quad N\left(-d_{S}^{m}\left(\frac{\omega_{0} \cdot \bar{\omega}}{L^{2}}\right), d_{T}^{m}\left(\frac{\omega_{0}}{F}\right),-\rho\right)
\end{aligned}
$$

where

$$
\begin{gathered}
d_{s}^{m}(x)=\frac{\ln x}{\sigma \sqrt{s-t}}+h^{m} \sqrt{s-t}, \quad \rho=\sqrt{\frac{S-t}{T-t}} \\
h^{\omega}=\frac{r-\beta+\frac{1}{2} \sigma^{2}}{\sigma}, \quad h^{B}=h^{\omega}-\sigma, \quad h^{G}=h^{B}-\theta \sigma \\
\theta=\frac{\sqrt{\left(h^{B}\right)^{2}+2 r}+h^{B}}{\sigma}
\end{gathered}
$$

The $Q^{G}$-measure is included for future reference.

Before applying this result to price the compound call, we will try to provide some intuition for the structure of the derived formula. Consider the probability of an event $A$ conditional on not hitting a barrier. By decomposing $A$ into complementary events we may write

$$
\begin{aligned}
Q\left(A, \tau_{T} \notin \theta_{T}, \tau_{S} \notin \theta_{S}\right)= & Q(A) \\
- & Q\left(A, \tau_{S} \in \theta_{S}\right) \\
- & Q\left(A, \tau_{T} \in \theta_{T}\right) \\
+ & Q\left(A, \tau_{T} \in \theta_{T}, \tau_{S} \in \theta_{S}\right)
\end{aligned}
$$


The total probability is the unconditional (as regards the barrier) probability (line 1) less the probability conditional on the barrier being hit before $S$ (line 2) less the probability conditional on it being hit between $S$ and $T$ (line 3 ) plus the probability of hitting the barrier both before $S$ and between $S$ and $T$ (line 4). This structure of this partition (with $A=\left\{\omega_{T}>F, \omega_{S}>\bar{\omega}\right\}$ ) is precisely that of the expression in Lemma 1.

The probability for the $\left\{A_{S}\right\}$-event is well known ${ }^{7}$ and is

Lemma 2 The probability of the in-the-money event $A_{S}$ under the probability measures $m=\{B, \omega, G\}$ are given by

$$
Q^{m}\left(A_{S}\right)=N\left(d_{S}^{m}\left(\frac{\omega_{0}}{\bar{\omega}}\right)\right)-\left(\frac{L}{\omega_{0}}\right)^{\frac{2}{\sigma} h^{m}} N\left(d_{S}^{m}\left(\frac{L^{2}}{\omega_{0} \cdot \bar{\omega}}\right)\right)
$$

where $h^{m}$ and $d_{S}^{m}(x)$ are given in Lemma 1 .

Applying these results to equation (2), we are now ready to state the price of the compound call.

Proposition 1 The price of a call with exercise price $K$ and maturity $S$ on a down-and-out call with exercise price $F$ of maturity $T$ is given by

$$
\begin{aligned}
C\left(C_{L}\left(\omega_{t}, t ; F, T\right), t ; K, S\right)= & e^{-\beta(T-t)} \omega_{0} \cdot Q^{\omega}\left(A_{T}\right)-e^{-r(T-t)} F \cdot Q^{B}\left(A_{T}\right) \\
& -e^{-r(S-t)} K \cdot Q^{B}\left(A_{S}\right)
\end{aligned}
$$

where the probabilities are given in Lemma 1 and Lemma 2.

To interpret the proposition note that a compound call, although formally a claim on the underlying call at $S$, is ultimately a claim on the assets of the firm at $T$. Technically, a compound call of maturity $S$ on a call of maturity of $T$ can therefore be viewed as a call of maturity $T$ on $\omega$ that pays off only if $\left\{\omega_{S}>\bar{\omega}\right\}$ less the value of the requirement to pay the exercise price at $S$. To help formalize this idea we make the following, slightly more general, definition.

Definition 3 For a general claim $Y$ maturing at $T>S$, its conditional counterpart, $\mathcal{Y}$, is defined using the pay-off functions

$$
\mathcal{Y}\left(\omega_{T}, T ; \cdot \mid A\right) \equiv Y\left(\omega_{T}, T ; \cdot\right) \times I_{\{A\}}
$$

\footnotetext{
${ }^{7}$ The event $A_{S}$ is the in-the-money event for a down-and-out call. The price of a downand-out call was first derived by Merton (1973)
} 
In particular, a conditional (down-and-out) call is a derivative that pays off as an ordinary (down-and-out) call option maturing at $T$, conditional on the compound call being in-the-money at $S$, i.e. $A=\left\{\tau_{S} \notin \theta_{S}, \omega_{S}>\bar{\omega}\right\}$ :

$$
\mathcal{C}_{L}\left(\omega_{T}, T ; F, T \mid \omega_{S}>\bar{\omega}\right) \equiv C_{L}\left(\omega_{T}, T ; F, T\right) \cdot I_{\left\{\omega_{S}>\bar{\omega}\right\}}
$$

As above, subscript ${ }_{L}$ is used to denote payoffs conditional on the event $\left\{\tau_{S} \notin \theta_{S}, \tau_{T} \notin \theta_{T}\right\}$. (Since the underlying claim is down-and-out, the condition $\left\{\tau_{S} \notin \theta_{S}\right\}$ in $A$ is superfluous.) We note the price of this claim as a corollary.

Corollary 1 The price of a conditional down-and-out call is

$$
\mathcal{C}_{L}\left(\omega_{t}, t ; F, T \mid \omega_{S}>\bar{\omega}\right)=e^{-\beta(T-t)} \omega_{0} \cdot Q^{\omega}\left(A_{T}\right)-e^{-r(T-t)} F \cdot Q^{B}\left(A_{T}\right)
$$

The result is derived in Appendix C.1.

Notice that the structure of the call formula is similar to that of the standard Black \& Scholes formula. Setting $\beta=K=L=0$ the expression collapses to the latter formula. The structure is not tied to the assumptions of constant asset volatility and interest rate - see Geman et al. (1995). However, they guarantee closed form solutions for the probabilities.

We can rewrite the price of the compound down-and-out call in Proposition 1 as

$$
C\left(C_{L}\left(\omega_{t}, t ; F, T\right), t ; K, S\right)=\mathcal{C}_{L}\left(\omega_{0} ; F, T \mid \omega_{S}>\bar{\omega}\right)-e^{-r(S-t)} K \cdot Q^{B}\left(A_{S}\right)
$$

This expression formalizes the interpretation above of a compound call ultimately being a claim on the firm's assets.

Consider now in more detail the conditional down-and-out call option. Remembering the probability decomposition in equation (3) we can write the call price as

$$
\begin{aligned}
\mathcal{C}_{L}\left(\cdot \mid \omega_{S}>\bar{\omega}\right)= & \mathcal{C}\left(\cdot \mid\left\{\omega_{S}>\bar{\omega}\right\}\right) \\
& -\mathcal{C}\left(\cdot \mid\left\{\omega_{S}>\bar{\omega}\right\} \cap\left\{\tau_{S} \in \theta_{S}\right\}\right) \\
& -\mathcal{C}\left(\cdot \mid\left\{\omega_{S}>\bar{\omega}\right\} \cap\left\{\tau_{T} \in \theta_{T}\right\}\right) \\
& +\mathcal{C}\left(\cdot \mid\left\{\omega_{S}>\bar{\omega}\right\} \cap\left\{\tau_{S} \in \theta_{S}\right\} \cap\left\{\tau_{T} \in \theta_{T}\right\}\right)
\end{aligned}
$$

The three last claims are thus down-and-in calls with different partial barrier arrangements. Similar options with barriers that only partially cover the options' lives are studied in Heynen \& Kat (1994), Carr (1995) and Bermin (1995). The conditional call will be useful for pricing more complex compound derivatives. 


\section{Options on Corporate Securities}

In this section we consider the pricing of options on corporate securities, extending the idea that the compound call could be interpreted as a option on equity in a firm with discount debt only. We begin by reviewing the valuation of the underlying securities, and then proceed to the options themselves. We conclude by briefly discussing the applicability of the results to other areas.

\subsection{Pricing Corporate Securities}

In the framework of Ericsson \& Reneby (1998) securities can be valued as portfolios of three simple building blocks. A full exposition of this idea would take up too much space and the reader is referred to that paper for details, but a general description of the method is as follows.

The valuation method exploits the fact that contracted payoffs to the company's securities can be replicated with payoffs from two basic claims: a call and a heaviside (a binary option paying off $\$ 1$ at maturity if the underlying exceeds the exercise price). Assuming the absence of arbitrage, two claims with identical payoff structures must have the same price. Hence to value a corporate security, one simply mimics the payoffs of that security with those of down-and-out calls $\left(C_{L}\right)$ and heavisides $\left(H_{L}\right)$. To capture the value of payoffs in financial distress, a down-and-in claim $\left(G^{L}\right)$ is also necessary. This claim pays off $\$ 1$ if and when default occurs prior to maturity and is therefore often termed a dollar-in-default. We collect the pricing formulas for the building blocks of Ericsson \& Reneby (1998) in the following three lemmata:

Lemma 3 The price of a down-and-out call is given by

$$
\begin{aligned}
C_{L}\left(\omega_{t}, t ; F, T\right)= & \omega_{t} e^{-\beta(T-t)} \cdot Q^{\omega}\left(\tau_{T} \notin \theta_{T}, \tau_{S} \notin \theta_{S}, \omega_{T}>F\right) \\
& -e^{-r(T-t)} F \cdot Q^{B}\left(\tau_{T} \notin \theta_{T}, \tau_{S} \notin \theta_{S}, \omega_{T}>F\right)
\end{aligned}
$$

with probabilities given by Lemma 2 with $S=T$ and $\bar{\omega}=F$.

Lemma 4 The price of a down-and-out heaviside is

$$
H_{L}\left(\omega_{t}, t ; F, T\right)=e^{-r(T-t)} \cdot Q^{B}\left(\tau_{T} \notin \theta_{T}, \tau_{S} \notin \theta_{S}, \omega_{T}>F\right)
$$

with probability given by Lemma 2 with $S=T$ and $\bar{\omega}=F$. 
Lemma 5 The price of a dollar-in-default claim is

$$
\begin{aligned}
G^{L}\left(\omega_{t}, t ; T\right)= & G^{L}\left(\omega_{t} ; \infty\right) \cdot\left(1-Q^{G}\left(\tau_{T} \notin \theta_{T}, \tau_{S} \notin \theta_{S}, \omega_{T}>L\right)\right) \\
& \text { with } \\
G^{L}\left(\omega_{t} ; \infty\right)= & \left(\frac{\omega_{t}}{L}\right)^{-\theta}
\end{aligned}
$$

with probability given by Lemma 2 with $S=T$ and $\bar{\omega}=L$ and $\theta$ given in Lemma 1.

We note in passing that $G^{L}\left(\omega_{t} ; \infty\right)$ is the perpetual dollar-in-default claim that we use to define the probability measure $Q^{G}$; the measure where prices normalized by this claim are martingales.

Proposition 1 in Ericsson \& Reneby (1998) gives us the value of a corporate security. For convenience, we restate it here as a lemma, where $\Phi\{x\}$ denotes the contracted payoff to a claim $x$.

Lemma 6 A corporate security $C S$ with contracted payments

$$
\Phi\{C S\}=\left\{\begin{array}{c}
\sum_{i} a^{(i)} \Phi\left(C_{L}\left(\omega_{t}, t ; F_{i}, t_{i}\right)\right) \\
+ \\
\sum_{i} b^{(i)} \Phi\left(H_{L}\left(\omega_{t}, t ; F_{i}, t_{i}\right)\right)
\end{array}\right.
$$

and an expected recovery fraction in case of default prior to maturity $\phi$, can be valued as

$$
C S\left(\omega_{t}, t ; \cdot\right)=\left\{\begin{array}{c}
\sum_{i} a^{(i)} C_{L}\left(\omega_{t}, t ; F_{i}, t_{i}\right) \\
+ \\
\sum_{i} b^{(i)} H_{L}\left(\omega_{t}, t ; F_{i}, t_{i}\right) \\
+ \\
\varphi \cdot L \cdot G^{L}\left(\omega_{t}, t ; T\right)
\end{array}\right.
$$

where " $i "$ is used to index calls and heavisides of different exercise prices $F_{i}$ and maturities $t_{i}$ and $a^{(i)}$ and $b^{(i)}$ are constants. The summation operator $\sum$ should be understood to encompass integrals when applicable.

For derivations and applications, we refer to Ericsson \& Reneby (1998). Below we just provide a simple example for future reference. 
Example $1 A$ bullet bond with coupon $c$ and face value $F<L$ of maturity $T$ and recovery rate $\psi$ is simply priced as a sum of heavisides plus the dollar-indefault claim:

$$
C S\left(\omega_{t}, t ; \cdot\right)=\left\{\begin{array}{c}
\sum_{i} c \cdot H_{L}\left(\omega_{t}, t ; L, t_{i}\right) \\
+F \cdot H_{L}\left(\omega_{t}, t ; L, T\right) \\
+\psi F \cdot G^{L}\left(\omega_{t}, t ; T\right)
\end{array}\right.
$$

\subsection{Pricing Options}

We now turn to the valuation of options. An issue that has to be addressed is what happens to the value of an option when the firm defaults. In other words, what is the value of the underlying corporate security after default? Since the securities are often no longer traded, their values are difficult to determine. We will assume that for purposes of determining the payoff to derivative holders there is a provision stating that corporate securities have a post-default value of zero. Thus, at expiration, a call option expires worthless whereas a put option takes on a value equal to the exercise price. We formalize this idea by defining the process determining derivative payoffs

$$
\widehat{C S}\left(\omega_{t}, t ; \cdot\right) \equiv C S\left(\omega_{t}, t ; \cdot\right) \cdot I_{\left\{\tau_{S} \notin \theta_{S}\right\}}
$$

Since corporate securities can be valued as down-and-out calls, heavisides and the dollar-in-default claim, an option on a corporate security can be valued as an option on a portfolio of these three contracts. Furthermore, an option on a portfolio can be treated as a portfolio of options on the parts. In the previous section, we defined conditional claims and saw that an option on an option could be valued as a conditional call. To value options on corporate securities, we make use of two more, analogous, building blocks: the conditional heaviside and the conditional dollar-in-default. The definitions follow directly from Definition 3 with $A=\left\{\tau_{S} \notin \theta_{S}, \omega_{S}>\bar{\omega}\right\}$ and pricing formulas are given in the following two corollaries:

Corollary 2 The price of a conditional heaviside is

$$
\mathcal{H}_{L}\left(\omega_{t}, t ; F, T \mid \omega_{S}>\bar{\omega}\right)=e^{-r(T-t)} Q^{B}\left(A_{T}\right)
$$


where the probability is given by Lemma 1. The result is derived in Appendix C.2.

Corollary 3 The price of a conditional dollar-in-default is

$$
\mathcal{G}^{L}\left(\omega_{t}, t ; T \mid \tau_{S} \notin \theta_{S}, \omega_{S}>\bar{\omega}\right)=G^{L}\left(\omega_{t} ; \infty\right) \cdot\left(Q^{G}\left(A_{S}\right)-Q^{G}\left(A_{T}\right)\right)
$$

where $G^{L}\left(\omega_{t} ; \infty\right)$ is given in Lemma 5 and the $Q^{G}$-probabilities are given by Lemmata 1 and 2, respectively. The result is derived in Appendix C.3.

With these building blocks at hand, the generalization of the compound call formula to a formula for a call option on a general corporate security is straightforward. From the risk-adjusted expected value of the call payoff, the call price can be expressed as

$$
C\left(C S_{t}, t ; K, S\right)=e^{-r(S-t)} \cdot E^{B}\left[\left(\widehat{C S}\left(\omega_{S}, S ; K, S\right)-K\right) \cdot I_{\left\{C S_{S}>K\right\}}\right]
$$

It follows directly from inserting the value of the corporate security in Lemma 6 into (6) that the option can be valued as a sum of conditional calls, heavisides and dollar-in-default claims:

Proposition 2 The price of a call option with maturity at $S$ and exercise price $K$ on the corporate security of Lemma 6 is given by

$$
C\left(\widehat{C S}_{t}, t ; K, S\right)=\left\{\begin{array}{c}
+\sum_{i} a^{(i)} \cdot \mathcal{C}_{L}\left(\omega_{t}, t ; F_{t_{i}}, t_{i} \mid \omega_{S}>\bar{\omega}\right) \\
\sum_{i} b^{(i)} \cdot \mathcal{H}_{L}\left(\omega_{t}, t ; F_{t_{i}}, t_{i} \mid \omega_{S}>\bar{\omega}\right) \\
+\varphi \cdot L \cdot \mathcal{G}^{L}\left(\omega_{t}, t ; T \mid \omega_{S}>\bar{\omega}, \tau_{S} \notin \theta_{S}\right) \\
-K \cdot H_{L}\left(\omega_{t}, t ; \bar{\omega}, S\right)
\end{array}\right.
$$

where $\bar{\omega}$ solves $C S_{S}=K$. The values of the conditional claims are given in corollaries above.

As can be seen by comparing this result with Lemma 6, the price of a call is analogous to the price of the underlying security - with conditional rather than ordinary down-and-out claims and an adjustment for the requirement to pay the exercise price ( $K$ down-and-out heavisides). 
Corollary 4 The price of a put option that matures at $S$ and with exercise price $K$ on the corporate security of Lemma 6 is given by put-call parity

$$
P\left(C S_{t}, t ; K, S\right)=e^{-r(S-t)} K-C S_{t}+C\left(C S_{t}, t ; K, S\right)
$$

If the put option is embedded, however, the put-call-parity relation does not hold with the call in Proposition 2. The embedded put option has a lesser value than the ordinary put since it runs the risk of becoming worthless if the firm defaults - and this is when the ordinary put is worth the most. Instead, the following relationship may be used.

Corollary 5 The price of an embedded put option on a corporate security may be calculated using the following formula:

$$
P\left(C S_{t}, t ; K, S\right)=K \cdot H_{L}\left(C S_{t}, t ; L, S\right)-C S_{t}+C\left(C S_{t}, t ; K, S\right)
$$

\subsection{Pricing Other Claims}

The proposed approach can readily be extended to value claims other than options on corporate securities. Basically any compound claim can be valued while allowing for a barrier. Below, we provide an example with a putable bond.

Another obvious application would be to debt and equity while allowing debt of two different maturities in the capital structure. Equity and short term debt would in such an environment be valued as compound barrier claims. A related area is financial guarantees, which could be valued as compound barrier claims on debt of different maturities. A similar approach could be used for warrants.

Moreover, as already noted in section 3, we have implicitly valued some compound down-and-in claims. Using the method of derivation in appendix, the analysis could easily be extended to a case with a single barrier of any type (up- or down, in- or out, partial or non partial), if one should find an interesting application for such a compound claim.

Even though the previous analysis has dealt with options as the compound claim, other derivatives can readily be valued as well as long as their payoffs can be replicated by calls and heavisides. One then needs two additional compound claims: the heaviside on a down-and-out call and the heaviside on a down-andout heaviside. These are just simpler versions of the compound claims in this paper. 
As an example of how to utilize this framework for options on corporate securities, consider a putable bond. A putable bond gives the holder the right to sell the bond back to the issuer prior to maturity. Typically, the put is "European-style" in that it can be exercised for a very short time only (Hardy (1995)). About 900 bonds had some kind of put feature by 1995 (Hardy (1995)).

Example 2 A putable bond. Assume that the holders of the straight coupon bond of Example 1 have an option to redeem it at par at time $S$. The value of this putable bond is the value of the original bond plus the put or, using the relation

in Corollary 5 above with $K=F$, the value of a number of $F$ down-and-out heavisides plus the corresponding call. Formally

$$
\begin{aligned}
C S\left(\omega_{t}, t ; \cdot \mid \text { putable }\right) & =C S\left(\omega_{t}, t ; \cdot\right)+P\left(C S_{t}, t ; F, S\right) \\
& =F \cdot H_{L}\left(\omega_{t}, t ; L, S\right)+C\left(C S_{t}, t ; L, S\right)
\end{aligned}
$$

Inserting the value of the call yields

$$
\begin{aligned}
C S\left(\omega_{t}, t ; \cdot \text { putable }\right)= & F \cdot H_{L}\left(\omega_{t}, t ; L, S\right) \\
& +\left\{\begin{array}{c}
\sum_{i} c \cdot \mathcal{H}_{L}\left(\omega_{t}, t ; L, t_{i} \mid C S_{S}>F\right) \\
+F \cdot \mathcal{H}_{L}\left(\omega_{t}, t ; L, T \mid C S_{S}>F\right) \\
+\psi F \cdot \mathcal{G}^{L}\left(\omega_{t}, t ; T \mid C S_{S}>F\right) \\
-F \cdot H_{L}\left(\omega_{t}, t ; \bar{\omega}, S\right)
\end{array}\right.
\end{aligned}
$$

To better understand the formula, think about the following two outcomes. If, on the expiration day of the put, the bond is worth more than par, the put is not utilized and the holder retains the bond. In the formula, this means that, at time $S, C S_{S}>F$ and the conditional claims are "transformed" to ordinary (unconditional) claims which, in aggregate, equal the value of the bond. The first and last terms are both equal to $P$ (since both heavisides are in-the-money) and consequently add to zero. The total sum thus is equal to the value of the bond, $C S_{S}=\sum_{i} c H_{L}+F \cdot H_{L}+\psi F \cdot G^{L}$. 
Contrarily, if on the expiration day of the put, the bond is worth less than par, the put is utilized and the holder obtains the principal. In the formula, the same result is obtained since $C S_{S}<F$ and the conditional claims expire worthless. The first term is equal to $P$, since this heaviside (having exercise price $L_{S}$ ) is in-the-money, but in this case the last term is equal to zero, since this heaviside (having exercise price $\bar{\omega}$ ) expires out-of-the-money. The total sum in this case is therefore equal to $P$.

Perhaps it would seem natural to also include callable bonds among the examples. However, as has been shown in theory (Kim et al. (1993)) as well as in practice (Duffee (1998)), the value of the call feature stems mainly from the interest rate risk. Since such risk is excluded from the setup of this thesis by assumption, the relevance of callability is diminished as well. Basically, credit risk is more relevant for putable than for callable bonds - with slight exaggeration, it is true that a callable bond is called when interest rates fall, and a putable bond is sold back to the firm when credit quality falls.

\section{Some Numerical Results}

This section presents some numerical results for the suggested option pricing model. Our choice of comparisons is partially dictated by existing models. We are able to nest the Geske (1979) model by setting the default barrier to zero and a version of the Toft \& Prucyk (1997) model by using perpetual continuous coupon debt.

We focus on the effect of the barrier and the finite debt maturity, since the combination of those features are the essence of the paper. This is the subject of the following two subsections. We assume no bankruptcy costs or taxes and also assume that the assets of the firm are traded to be able to conduct the comparative analysis in a straightforward manner. In this setting the value of the firm equals the value of assets, and hence two firms with equal asset value and leverage will also have the same debt and equity values. This is convenient for comparing different pricing models consistently. Moreover, to isolate the effect of the barrier and the maturity of debt we refrain from introducing coupons until later. Throughout we limit ourselves to considering a European call option only, which in this setting simply will be equal to the compound option of Proposition 1. 
We investigate the effects of coupons in the third subsection (5.3).

\subsection{The Effect of The Barrier}

It is the future evolution of the value of equity that governs the price of the option. Therefore, it will be useful to begin the analysis by looking at the effect of a barrier on the distribution of the stock price. The following figure plots the distribution for three different levels of the default barrier. Leverage is held constant by varying the principal of debt. Hence we have the same current stock price for all three scenarios although the time $S$ expectations may differ.

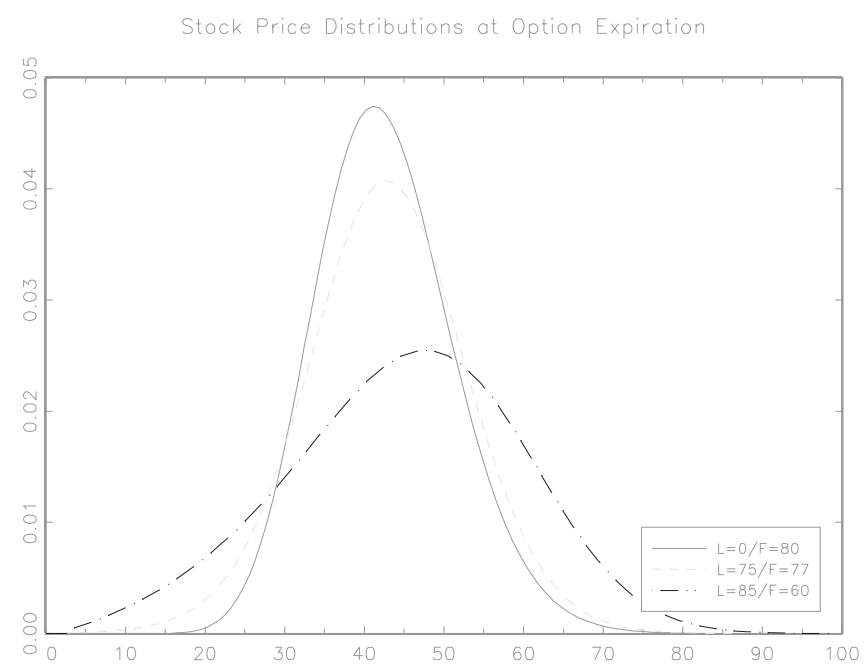

Figure 1: The EFFECT OF THE DEFAULT BARRIER ON STOCK PRICE DISTRIBUtions AT EXPIRATion. $\sigma=0.15, r=0.06, T=5, S=5 / 12$, current equity price 41.4 .

Most notably an increased barrier will yield an increase in stock price volatility. The higher barrier increases the probability that the stock becomes worthless. Furthermore since the principal is lower for the high barrier cases the probability of high stock prices will also increase; the intuition being that when default is unlikely shareholders are better off with a lower principal. This effect on stock price volatility will drive most of the results we present below. 
We start by analysing the barrier's influence on prices, then study the influence on hedge ratios and conclude by looking at the effects of using the Black \& Scholes' model to calculate implied volatilities.

\subsubsection{The Effect on Prices}

A hypothetical trader observes market values of equity and debt but values options using a non barrier model and we can thus calculate the effect of omitting the barrier. He will select the principal of debt so that his model matches observed market prices of the corporate securities, and thereafter compute the option price. An option price ratio is obtained by dividing this option price by the true option price.

The following figure plots the option price ratio against leverage. The firm's leverage ratio is increased by decreasing the asset value of the firm. For each leverage, the exercise price of the option is set so as to place it at-the-money. The figure thus shows how the pricing error, resulting from using a non-barrier model for an at-the-money option, is affected by the leverage of the firm.

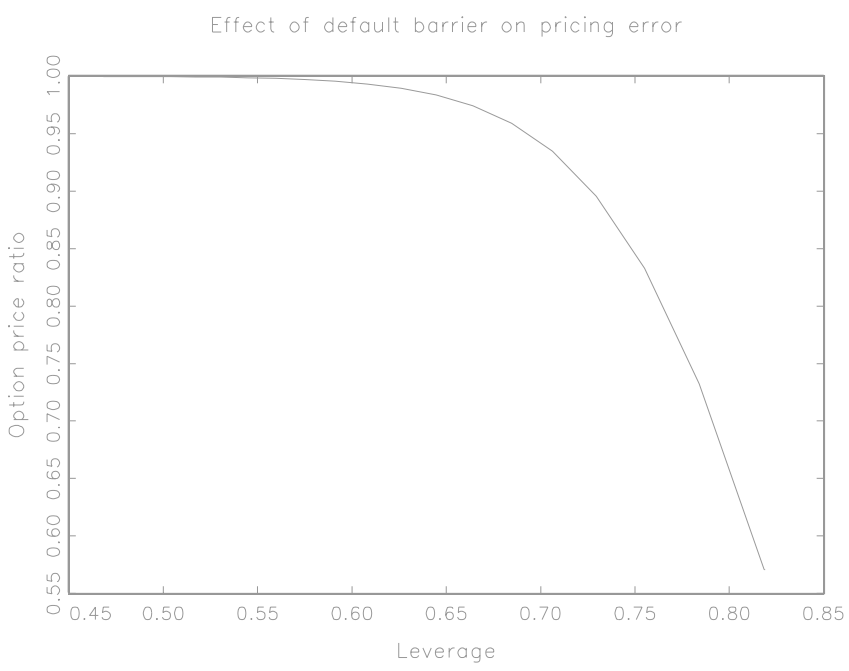

Figure 2: Default BARRIER AND OPTION PRICES. The ratio between option prices calculates using models without and with barrier respectively. $L=50, \omega_{0}=51 \ldots 100, \sigma=0.15, r=0.06, T=5, F=65, S=5 / 12, K=$ at-themoney. 
We note that the non-barrier model will underprice the option in general and that this error becomes more significant the higher the leverage. The most important effect at work here is that the non-barrier model will underestimate stock price volatility and hence option prices. The higher the leverage (the closer the asset value is to the barrier) the higher the equity volatility, and the more crucial the effect of neglecting the barrier becomes.

\subsubsection{The Effect on Deltas}

In this section we study the option delta $(\Delta)$ - its sensitivity to changes in the underlying stock price. Below we plot both barrier and non barrier deltas (hedge ratios) as a function of the stock price.

Consider a call option. As the stock price increases as a result of an increase in the underlying asset value the likelihood of default decreases. As this happens the deltas converge for the two models - that of the barrier model approaches from below.

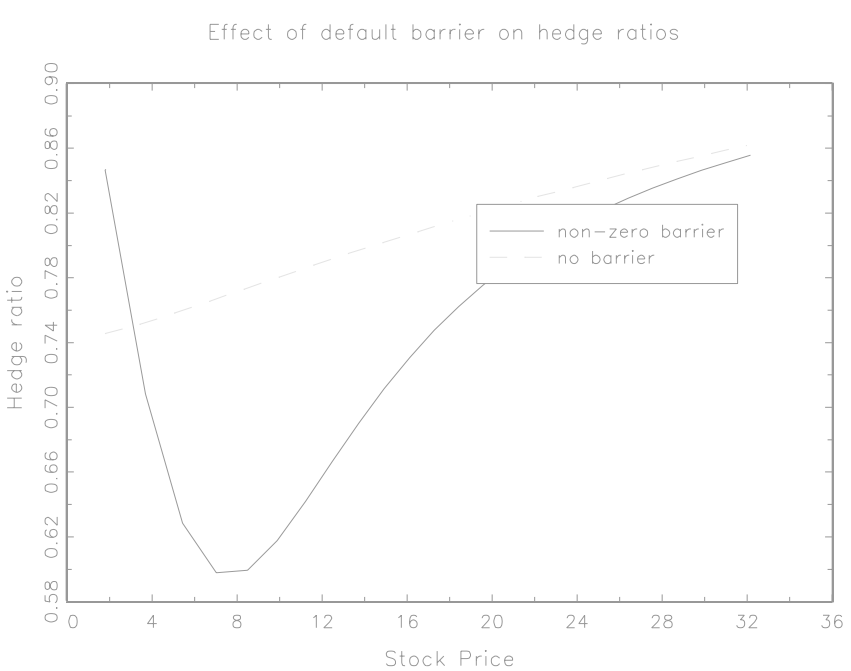

Figure 3: Default barRier And hedge Ratios. The deltas for barrier and non-barrier models as functions of the underlying stock price. $L=50, \omega_{0}=$ $51, \ldots, 100, \sigma=0.15, r=0.06, T=5, F=65$. Option is at-the-money.

When one approaches financial distress the deltas may differ considerably. 
Initially the delta for the option in the barrier model decreases relative to that of the standard compound option model. Then as default becomes more imminent the relationship is reversed and the delta of the barrier option pricing model may exceed the non barrier one considerably. This indicates that the higher sensitivity of standard barrier contingent claims prices near the barrier carries over to compound barrier options.

In practice, these results would translate into the following situation. Suppose that a trader uses the non-barrier model to replicate a long position in the call in a situation where a barrier is an important determinant of option prices. If financial distress is imminent he will underinvest in the underlying stock. On the other hand as the firm becomes less likely to default his hedge portfolio may consist of too much stock.

Investigating in- and out-of-the-money options shows that deltas are familiarly increasing the deeper in-the-money they are.

\subsubsection{The Effect on Implied Volatilities}

Equity volatilities are in practice often estimated as the volatilities implied by the Black \& Scholes model from traded option prices. If it were a correct description of reality, all options written on the same stock would of course imply the same equity volatility. However, one usually finds that implied volatilities increase the deeper in-the-money the options are (the volatility "smirk") - this is equivalent to overpricing in-the-money call options, see for example Rubinstein (1994).

Below, we plot implied volatilities (normalized by the at-the-money implied volatility) as a function of the exercise to stock price ratio. Again, we let our model represent reality, and hence yield correct prices. Implied volatilities are calculated using the Black \& Scholes' model. Moreover, this is done for several levels of the barrier, $L$. For each choice of $L$ in the figure below we adjust the principal of debt so that the market value of equity (and hence leverage) is held constant. Thus, the figure indicates how the volatility "smirk" is influenced by a barrier.

As can be seen, the volatility smirk becomes more pronounced the higher the barrier. The explanation is as follows. Equity volatility decreases (increases) with increases (decreases) in the asset value due to a lower (higher) leverage. This effect obtains even with $L=0$ and leads to relatively higher values (and 


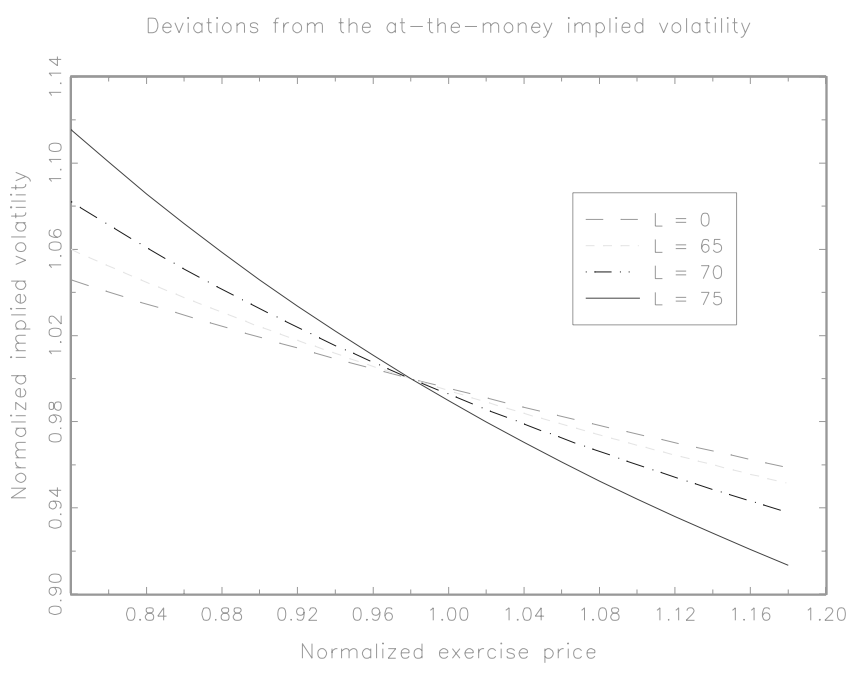

Figure 4: Default BarRier And ImPlied volatilities. Implied volatilities normalized by the at-the-money implied volatility as a function of the normalized exercise price. $\omega_{0}=100, \sigma=0.15, r=0.06, T=5, F=82.05 / 81.77 /$ $81.10 / 79.31$. Leverage is $60 \%$ and $S=4 / 12$

thus implied volatilities) for in-the-money calls and relatively lower for out-ofthe-money calls. This explains the general downward sloping curve shape of the volatility skew. Furthermore this leverage effect is amplified by a higher default barrier. The model of Toft \& Prucyk (1997) yields the same pattern. Furthermore they find empirical support for such leverage driven pricing biases.

\subsection{The Effect of Debt Maturity}

In this section we briefly analyse how the maturity of debt affects the value of the option. It is done in the following way. First option prices in-, at-, and out-of-the-money are calculated for a benchmark maturity of $T=5$ years. Then the price changes resulting from a change of debt maturity are calculated. The stock price is held constant at 41 throughout by varying the principal. The described procedure can thus be interpreted as the effect on the option price from a change in the capital structure that would leave both debt and equity holders indifferent. 


\begin{tabular}{llll}
\hline \hline & & & \\
& $\begin{array}{l}T=1 \\
(F=62) \\
\text { (price change) }\end{array}$ & $\begin{array}{c}T=5 \\
(F=80) \\
\text { (price) }\end{array}$ & $\begin{array}{l}T=10 \\
(F=118) \\
\text { (price change) }\end{array}$ \\
& & & \\
\hline In-the-money option $(\mathrm{K}=33)$ & $+3.2 \%$ & 9.85 & $-1.2 \%$ \\
At-the-money option $(\mathrm{E}=\mathrm{K}=41)$ & $+6.4 \%$ & 4.41 & $-5.0 \%$ \\
Out-of-the-money option $(\mathrm{K}=50)$ & $+11.2 \%$ & 1.26 & $-12.6 \%$ \\
& & & \\
\hline \hline
\end{tabular}

Table 1 indicates that the maturity of debt influences option prices significantly. Again, the reason is volatility - the longer the maturity, the lower the volatility of equity during the lifetime of the option since the impact of the principal is weakened.

The influence of volatility increases with out-of-the-moneyness. The reason is the well known observation that out-of-the-money calls "have nothing to loose" from increased risk - only the right tail of the stock price distribution affects the call price (in contrast to the price of an in-the-money option).

In section 5.3.3 we look at the effects of approximating debt of finite maturity with infinite maturity when coupons are paid continuously.

\subsection{Some Additional Numerical Results}

In this section we introduce coupons, bankruptcy costs, (corporate) taxes and violation of the absolute priority rule (APR). The notion of bankruptcy costs should be interpreted as the total decrease in asset value at the time of default that occurs before any distribution to debt- and equity holders. Thus this includes not only direct costs such as legal fees, deferred taxes and wages which have priority but also indirect costs such as production disturbances and damaged reputation. A violation of the APR is modelled as the percentage of the firms assets less bankruptcy costs that are distributed to shareholders following 
financial distress ${ }^{8}$ - even though they are formally not entitled to it.

\subsubsection{Time Passes}

The intention of this section is to exemplify pricing of options in a more realistic setting and to illustrate the quantitative price change of a European call option as time passes. We will also see how the pricing biases of alternative models change.

We will use the following set of parameters:

\begin{tabular}{|c|c|c|c|c|c|c|}
\hline \multicolumn{7}{|c|}{ External factors } \\
\hline$\omega_{0}$ & $r$ & $\beta$ & $\sigma$ & Tax rate & Violation of APR & Bankruptcy costs \\
\hline \multirow[t]{4}{*}{100} & 0.06 & 0 & 0.15 & 0.35 & 0.08 & 10 \\
\hline & & \multicolumn{3}{|c|}{ Capital structure } & \multicolumn{2}{|c|}{ Option contract details } \\
\hline & & $F$ & $c$ & $T$ & $K$ & $S$ \\
\hline & & 60 & 0.08 & 50 & at-the-mone & $\frac{5}{12}$ \\
\hline
\end{tabular}

The coupon is paid semi-annually. The setup above gives rise to the following capital structure:

\begin{tabular}{ll}
\hline \hline Value of the firm & 106 \\
Equity $\left(\sigma_{E}=34 \%\right)$ & 43 \\
Debt & 63 \\
Leverage & $59 \%$ \\
\hline \hline
\end{tabular}

The tax shield is worth 6.5. The price of the call option is 4.37. The Black $\&$ Scholes' and the non-barrier models produce a modest underpricing of $1 \%$ and $2 \%$, respectively.

Now consider what happens to the value of the option as time passes. The following table contains future option prices for different scenarios. For five "reasonable" (given an asset volatility of 15\%) outcomes of $\omega$ in three months it gives the corresponding equity and option prices. It also shows how the pricing

${ }^{8}$ That is $[$ violation of $A P R]=\frac{[\text { to equityholders }]}{L-[\text { bankruptcy costs }]}$. 
biases of two alternative models change (NB abbreviates non barrier ${ }^{9}$ and $\mathrm{BS}$ abbreviates Black \& Scholes) .

Table 2: 3 MONTHS LATER - 2 MONTHS TO EXPIRATION $(\mathrm{T}=0.25)$.

\begin{tabular}{lllll}
\hline \hline \multirow{2}{*}{$\omega_{0.25}$} & Equity & Option & NB price & BS price \\
& value & price & bias & bias \\
\hline
\end{tabular}

\begin{tabular}{rllll}
\hline 104 & $47(+7.1 \%)$ & 4.64 & $-1 \%$ & $-1 \%$ \\
102 & $45(+2.6 \%)$ & 3.30 & $-1 \%$ & $-1 \%$ \\
100 & $43(-1.9 \%)$ & 2.12 & $-2 \%$ & $\pm 0 \%$ \\
98 & $41(-6.5 \%)$ & 1.38 & $-4 \%$ & $+3 \%$ \\
96 & $39(-11 \%)$ & 0.80 & $-6 \%$ & $+7 \%$ \\
& & & \\
\hline \hline $50, \sigma=0.15,8 \%$ deviations from APR, $r=0.06, \beta=0, T=4.75$,
\end{tabular}

The next table contains five possible scenarios yet 7 weeks later (1 week prior to expiration) for the same option.

The pricing biases increase as expiration approaches and as equity value falls, driving the options out-of-the-money. This is the same story that was told before. As equity value falls, the downward volatility bias increases for the non barrier model. And the more out-of-the-money the option is, the more it would stand to gain from a higher volatility.

For the Black \& Scholes' model, however, the opposite is true - the model uses the correct (instantaneous) equity volatility. But since it is assumed that it is constant, it fails to take into account that volatility actually decreases when equity increases (due to lowered leverage). This overestimation of volatility at higher stock prices is particularly noticeable for out-of-the-money options.

\footnotetext{
${ }^{9}$ With coupons, it is no longer obvious what maturity of debt the non barrier user should choose when applying his model. As suggested by Geske (1979), maturity of debt is chosen to match the (riskfree) duration of the true debt contract.
} 
Table 3: 4.75 MONTHS LATER - 1 WEEK TO EXPIRATION $(\mathrm{T}=0.4)$

\begin{tabular}{|c|c|c|c|c|}
\hline$\omega_{0.4}$ & equity change & option price & NB price bias & BS price bias \\
\hline 106 & $48(+11 \%)$ & 4.65 & $\pm 0 \%$ & $\pm 0 \%$ \\
\hline 103 & $45(+3.7 \%)$ & 1.94 & $\pm 0 \%$ & $\pm 0 \%$ \\
\hline 100 & $42(-3.1 \%)$ & 0.36 & $-4 \%$ & $+3 \%$ \\
\hline 97 & $39(-10 \%)$ & 0.02 & $-14 \%$ & $+21 \%$ \\
\hline 94 & $36(-17 \%)$ & 0.00 & $-34 \%$ & $+209 \%$ \\
\hline
\end{tabular}

Bankruptcy Costs and Taxes The presence of bankruptcy costs does, ceteris paribus, mainly affect debt value. Only for very high leverages does it effect the value of equity and equity options ${ }^{10}$ (when the asset value is close to the barrier). When there are deviations from absolute priority, equity will loose value from an increase in bankruptcy costs - and hence the option price will decrease.

The effect of taxes are difficult to analyse since a change affects $\omega$ - the after$\operatorname{tax}$ value of assets - in an exogenous way. ${ }^{11}$ It is not possible in the model to determine the increase in the value of assets following a decrease in the tax rate - a comparison of option prices when taxes are high and low would therefore be dubious. We can, however, compare the mispricing of the alternative models in a world with and without taxes. Doing so, we obtain results equivalent to those with low and high coupons - taxes merely serve to lower the cost of coupon payments.

Concluding, taxes and bankruptcy costs are an important determinant of equity option prices only indirectly. They have to be modelled for purposes of matching equity and debt values implied by the model with true values.

\footnotetext{
${ }^{10}$ For debt and debt derivatives, bankruptcy costs are of course bound to have a larger effect.

${ }^{11}$ Potentially, a changed tax rate may also affect $(\mu, \lambda, \sigma)$.
} 
Table 4: EFFECT OF FIRST COUPON PAYMENT

\begin{tabular}{|c|c|c|c|}
\hline Firs & coupon payment in... & option price & NB price bias \\
\hline \multirow{2}{*}{$\underset{(T=4.75)}{3 \text { months }}$} & Expiration before $(\mathrm{S}=2 / 12)$ & 2.63 & $-2 \%$ \\
\hline & Expiration after $(S=4 / 12)$ & 4.70 & $-20 \%$ \\
\hline \multirow{2}{*}{$\ldots 6 \underset{(T=5))}{\text { months }}$} & Expiration before $(\mathrm{S}=5 / 12)$ & 4.37 & $-2 \%$ \\
\hline & Expiration after $(S=7 / 12)$ & 6.12 & $-15 \%$ \\
\hline \multicolumn{4}{|c|}{$\begin{array}{c}L=50, \omega_{0}=100, \sigma=0.15,8 \% \text { deviations from } \mathrm{APR}=0.08, r=0.06, \\
=4.75 / 5, c=0.08, F=60, S=2 / 12, K=\text { at-the-money, } B C=10, \text { taxes } \\
35 \% .\end{array}$} \\
\hline
\end{tabular}

\subsubsection{Option Maturity and the First Coupon Payment}

The option price is sensitive to whether the option matures before or after a coupon payment. Table 4 gives the true option price and the pricing bias using a non barrier (and thus non coupon) model for different combinations of option and coupon maturities. As can be seen, the mispricing of the non barrier model dramatically increases when there is a coupon payment during the lifetime of the option. Moreover, the effect increases when the coupon payment is more imminent, that is when its impact on equity prices and its volatility is larger. The explanation is the following.

Immediately after a coupon payment equity increases by the amount of the coupon. This explains why the option increases from 2.63 (4.37) to 4.70 (6.12) when its maturity is increased with 2 months. This effect is of course neglected in a model without coupons. Only the "usual" time-to-maturity effect increases option prices in that case.

\subsubsection{Continuous Coupon Payments}

An alternative to modelling discrete coupons, is to use an approximation with continuous payments. This section briefly looks at the potential effects of such an approximation.

For the option in the section termed Time Passes, the continuous coupon 
Table 5: Price Bias as a Result of approximating finite With infinite MATURITY DEBT

\begin{tabular}{ccc}
\hline \hline Capital structure & Option price & Option price bias $(T=\infty, c=5.2 \%)$ \\
\hline & & \\
$T=2.5, c=0 \%$ & 4.28 & $+19 \%$ \\
$T=5, c=2.7 \%$ & 4.67 & $+8 \%$ \\
$T=10, c=4.2 \%$ & 4.90 & $+3.5 \%$ \\
& & \\
\hline \hline
\end{tabular}

model overestimates the price with $15 \%$. This magnitude of overpricing extends to a wide range of underlying capital structures. On expiration of the option the equity price will be heavily influenced by the imminent coupon payment, which lowers the expected value of equity and hence the value of the option. In the continuous coupon model this effect will be much less pronounced, since the burden of the coupon is spread over time.

The closer the coupon payment follows the expiration of the option, the more the continuous coupon model overprices. If, on the other hand, the expiration of the option follows immediately after the coupon payment, the pricing bias is negligible.

Infinite Maturity Approximation with Continuous Coupons This section takes a brief look at what happens when finite maturity debt is approximated by infinite maturity debt. To focus on the maturity effect (and not the discrete/continuous coupon effect) we use continuous coupons throughout. First we calculate call option prices for different maturities of debt keeping leverage constant (at $60 \%$ ) by varying the coupon. Then the coupon necessary to obtain the same leverage in an infinite maturity environment and the corresponding option price are computed. This corresponds to a trader implementing an erroneous (infinite maturity) model. Table 5 shows the resulting price biases (when the true price is given by the finite maturity model).

As can be seen, overestimation of option prices when using an infinite maturity approximation may be far from negligible. The reason using an infinite maturity overestimates option prices is that a higher coupon rate means that 
a larger fraction of debt value will be repaid during the lifetime of the option. The expected value of equity at maturity of the option is therefore higher in the infinite maturity (high coupon) case. Therefore, the value of the option will be higher as well. Moreover (not shown in the table), overestimation increases with out-of-the-moneyness and maturity of the option.

Note that to apply a continuous coupon, infinite maturity approximation to a discrete coupon, finite maturity reality results in two sources of bias - both of which are positive.

\section{Concluding Remarks}

We have achieved two things in this paper. First we have presented an extension of Geske's compound option pricing model to the case of an option on a down-and-out call. Second we provide a general and unified method for pricing (analytically) both credit risky corporate securities and related derivatives in an environment where their volatility is driven by changes in leverage.

Numerical results show that using alternative models that do not account for intermediate financial distress may result in considerable pricing errors when leverage is high and especially when financial distress is likely. The pricing biases also carry over to the hedge parameters which may be both over- and underestimated. The suggested model is consistent with the volatility "smirk" effect observed in practice. The driving force of these results is that models that do not incorporate a default barrier may implicitly underestimate equity volatility and thus option prices.

Furthermore our results suggest the importance of accommodating a finite maturity. Detailed capital structure information - in particular the size and timing of coupon payments - has an important impact on option prices.

In summary, the comparative advantage of our model is precisely that it is capable of incorporating comprehensive balance sheet data. Suppose we want to price an option. Often good estimates of the underlying volatility can be extracted from market data. However if the derivative we want to price is part of, say, a debt issue which will affect the capital structure as a whole, it will be far more difficult to obtain a reliable estimate. In such a situation the model we suggest appears an appealing alternative. Since the model can directly incorporate the changes in the capital structure the volatilities of the 
underlying securities will reflect the impact of the new issue.

\section{References}

Bermin, H. P. (1995), 'Time and path dependent options: the case of time dependent inside and outside barrier options', Working Paper Lund University

Björk, T. (1994), 'Barrier contracts, ladders and lookbacks', Working Paper, Royal Institute of Technology, Sweden. .

Black, F. \& Cox, J. C. (1976), 'Valuing corporate securities: Some effects of bond indenture provisions', Journal of Finance 31, 351-67.

Black, F. \& Scholes, M. (1973), 'The pricing of options and corporate liabilities', Journal of Political Economy pp. 637-653.

Carr, P. (1995), 'Two extensions to barrier option valuation', Applied Mathematical Finance pp. 173-209.

Duffee, G. R. (1998), 'The relation between treasury yields and corporate bond yield spreads', Journal of Finance 53, 2225-2241.

Ericsson, J. (2000), 'Asset substitution, debt pricing, optimal leverage and maturity', Finance 21, 39-69.

Ericsson, J. \& Reneby, J. (1998), 'A framework for valuing corporate securities', Applied Mathematical Finance 5, 143-163.

Ericsson, J. \& Reneby, J. (1999), 'A note on contingent claims pricing with non-traded assets', Stockholm School of Economics Working paper No. 314.

Geman, H., El-Karoui, N. \& Rochet, J.-C. (1995), 'Changes of numeraire, changes of probability measure and option pricing', Journal of Applied Probability 32 pp. $443-458$.

Geske, R. (1979), 'The valuation of compound options', Journal of Financial Economics 7 pp. 63-81.

Hardy, E. S. (1995), 'Power to the creditors', Forbes p. 148. 
Heynen, R. \& Kat, H. (1994), 'Partial barrier options', Working Paper MeesPierson .

Kim, I., Ramaswamy, K. \& Sundaresan, S. (1993), 'Does default risk in coupons affect the valuation of corporate bonds?: A contingent claims model', Financial Management, Special Issue on Financial Distress .

Leland, H. (1994), 'Risky debt, bond covenants and optimal capital structure', The Journal of Finance 49. pp. 1213-1252.

Leland, H. \& Toft, K. B. (1996), 'Optimal capital structure, endogenous bankruptcy and the term structure of credit spreads', Journal of Finance No. 3 Vol. 51 pp. $987-1019$.

Longstaff, F. A. \& Schwartz, E. S. (1995), 'A simple approach to valuing risky fixed and floating rate debt', The Journal of Finance 50, 789-819.

Merton, R. C. (1973), 'The theory of rational option pricing', Bell Journal of Economics and Management Science Vol. 4, No. 1.

Merton, R. C. (1974), 'On the pricing of corporate debt: The risk structure of interest rates', Journal of Finance 29, 449-4790.

Nielsen, L. T., Saa-Requejo, J. \& Santa-Clara, P. (1993), 'Default risk and interest rate risk: The term structure of default spreads', Working paper INSEAD .

Reneby, J. (1998), Pricing Corporate Debt, PhD thesis, Stockholm School of Economics.

Rich, D. (1994), 'The mathematical foundations of barrier option-pricing theory', Advances in Futures and Options Research, Volume \%. pp. 267-311.

Rubinstein, M. (1994), 'Implied binomial trees', The Journal of Finance 49 pp. 771-818.

Toft, K. B. \& Prucyk, B. (1997), 'Options on leveraged equity: Theory and empirical tests', Journal of Finance 52 (3), 1151-1180. 


\section{A Preliminaries}

- $R^{j \rightarrow m}$ denotes the Radon-Nikodym derivative $R^{j \rightarrow m}=\frac{d Q^{m}}{d Q^{j}}$ with associated Girsanov-kernel $h^{j \rightarrow m}$. Thus superscripts " $j \rightarrow m$ " can be read from probability measure 'j' to probability measure ' $m$ '.

- To change measure one uses $d W^{X}=d W^{B}+h^{B \rightarrow X} d t$

\section{A.1 The default process}

Define the default process

$$
\left\{\begin{array}{l}
X_{t} \equiv \frac{1}{\sigma} \ln \frac{\omega_{t}}{L} \\
X_{0} \equiv \frac{1}{\sigma} \ln \frac{\omega_{0}}{L}
\end{array}\right.
$$

Default is defined through

$$
X_{\tau} \equiv 0
$$

The dynamics of the default process are

$$
d X=\mu_{X}^{m} d t+d W^{m}
$$

where $W^{m}$ is a Wiener-process under probability measure $Q^{m}$ and $\mu_{X}^{m}$ is its appurtenant drift.

- $Q^{B}$ is the measure under which price processes normalized with the money market account are martingales (the pricing measure)

- $Q^{\omega}$ is the measure under which price processes normalized with

$$
\omega_{t}^{\prime} \equiv e^{-r T} E^{B}\left[\omega_{T}\right]=e^{-\beta(T-t)} \omega_{t}
$$

are martingales. The Girsanov kernel used to go from the pricing measure is $h^{B \rightarrow \omega}=-\sigma$.

- $Q^{G}$ is the measure under which price processes normalized with $G^{L}\left(\omega_{t} ; \cdot\right)$ are martingales. The Girsanov kernel used to go from the pricing measure is $h^{B \rightarrow G}=\theta \cdot \sigma$.

- $Q^{X}$ is the measure under which $X$ is a martingale. The Girsanov kernel used to go from the pricing measure is obviously $h^{B \rightarrow X}=\mu_{X}^{B}$. 
The relevant drifts are

$$
\begin{aligned}
& \mu_{X}=\frac{\mu-\beta-0.5 \sigma^{2}}{\sigma} \\
& \mu_{X}^{B}=\frac{r-\beta-0.5 \sigma^{2}}{\sigma} \\
& \mu_{X}^{\omega}=\frac{r-\beta+0.5 \sigma^{2}}{\sigma} \\
& \mu_{X}^{G}=-\sqrt{\left(\mu_{X}^{B}\right)^{2}+2 r} \\
& \mu_{X}^{X} \equiv 0
\end{aligned}
$$

\section{A.2 Numeraires and change of probability measures}

Loosely speaking it holds that, for a general measure $Q^{j}$,

$$
E^{j}[m \cdot Y]=E^{j}[m] \cdot E^{m}[Y]
$$

where $E^{m}$ is the expected value under the probability measure $Q^{m}$ defined through

$$
\left\{\begin{array}{c}
d Q^{m}=R^{j \rightarrow m} d Q^{j} \\
R^{j \rightarrow m}=\frac{m}{E^{j}[m]}
\end{array}\right.
$$

The corresponding Girsanov-kernel is denoted $h^{j \rightarrow m}$. See e.g. Geman et al. (1995).

\section{A.3 First passage time}

First note that the first passage time density at 0 for process the $X_{t}$ under probability measure $Q^{m}$

$$
f^{m}\left\{X_{t} ; s\right\}=\frac{X_{t}}{\sqrt{2 \pi(s-t)^{3}}} e^{-\frac{1}{2}\left(\frac{X_{t}+\mu_{X}^{m}(s-t)}{\sqrt{s-t}}\right)^{2}}
$$

Remark 1 It holds that for a density function for a process like (7) with drift $\mu_{X}^{m}$

$$
\int_{t}^{\infty} e^{-\rho(s-t)} f^{m}\left\{X_{t} ; s\right\} d s=e^{-X_{t}\left(\sqrt{\left(\mu_{X}^{m}\right)^{2}+2 \rho}+\mu_{X}^{m}\right)}
$$


if $\left(\mu_{X}^{m}\right)^{2}+2 \rho \geq 0$. See e.g. Ericsson (2000) pp. 139-140.

\section{B Deriving Lemma 1}

Consider the expression (for notational convenience, set the time of pricing equal to zero: $t=0$ )

$$
Q^{m}\left(A_{T}\right)=E^{m}\left[I_{\left\{\omega_{T}>F, \omega_{S}>\bar{\omega}, \tau_{S} \notin \theta_{S}, \tau_{T} \notin \theta_{T}\right\}}\right]
$$

for $m=\omega, B, G$. Defining the normalized exercise prices at time $S$ and $T$

$$
\bar{\omega}_{X} \equiv \frac{1}{\sigma} \ln \frac{\bar{\omega}}{L} \quad F_{X} \equiv \frac{1}{\sigma} \ln \frac{F}{L}
$$

we can write

$$
Q^{m}\left(A_{T}\right)=E^{m}\left[I_{\left\{X_{T}>F_{X}, X_{S}>\bar{\omega}_{X}, \tau_{S} \notin \theta_{S}, \tau_{T} \notin \theta_{T}\right\}}\right]
$$

To remove the drift of the $X$-process, define (implicitly) the measure $Q^{X}$ (under which $X$ is a Wiener process) with associated Radon-Nikodym derivative:

$$
d Q^{m}=R^{X \rightarrow m} d Q^{X} \quad \text { with } \quad R^{X \rightarrow m}=e^{h^{X \rightarrow m} W_{T}^{X}-\frac{1}{2}\left(h^{X \rightarrow m}\right)^{2} T}
$$

With the help of this new probability measure we can rewrite (9) as

$$
\begin{aligned}
Q^{m}\left(A_{T}\right) & =E^{X}\left[R^{X \rightarrow m} \cdot I_{\left\{X_{T}>F_{X}, X_{S}>\bar{\omega}_{X}, \tau_{S} \notin \theta_{S}, \tau_{T} \notin \theta_{T}\right\}}\right] \\
& =\int_{F_{X}}^{\infty} \int_{\bar{\omega}_{X}}^{\infty} R^{X \rightarrow m} Q^{X}\left(X_{T} \in d x_{t}, X_{S} \in d x_{t}, \tau_{S} \notin \theta_{S}, \tau_{T} \notin \theta\{10)\right.
\end{aligned}
$$

where $x_{t}$ denotes a specific realisation of the default process $X_{t}$.

The term $Q^{X}\left(X_{T} \in d x_{T}, X_{S} \in d x_{S}, \tau_{S} \notin \theta_{S}, \tau_{T} \notin \theta_{T}\right)$ can safely be thought of as the probability of the Wiener process $X_{t}$ passing through the infinitesimal intervals $d x_{S}$ at $S$ and $d x_{T}$ at $T$ without hitting or having hit zero. The next step is to derive this density. 


\section{B.1 The $Q^{X}$-density function}

The corresponding cumulative probability can, by complementarity, be rewritten as

$$
\begin{aligned}
& Q^{X}\left(X_{T}>F_{X}, X_{S}>\bar{\omega}_{X}, \tau_{S} \notin \theta_{S}, \tau_{T} \notin \theta_{T}\right) \\
= & Q^{X}\left(X_{T}>F_{X}, X_{S}>\bar{\omega}_{X}\right) \\
& -Q^{X}\left(X_{T}>F_{X}, X_{S}>\bar{\omega}_{X}, \tau_{S} \in \theta_{S}\right) \\
& -Q^{X}\left(X_{T}>F_{X}, X_{S}>\bar{\omega}_{X}, \tau_{S} \notin \theta_{S}, \tau_{T} \in \theta_{T}\right) \\
& +Q^{X}\left(X_{T}>F_{X}, X_{S}>\bar{\omega}_{X}, \tau_{S} \in \theta_{S}, \tau_{T} \in \theta_{T}\right)
\end{aligned}
$$

Applying the reflection principle on the three latter terms yields

$$
\left\{\begin{array}{c}
Q^{X}\left(X_{T}>F_{X}, X_{S}>\bar{\omega}_{X}, \tau_{S} \in \theta_{S}\right)=Q^{X}\left(X_{T}<-F_{X}, X_{S}<-\bar{\omega}_{X}\right) \\
Q^{X}\left(X_{T}>F_{X}, X_{S}>\bar{\omega}_{X}, \tau_{S} \notin \theta_{S}, \tau_{T} \in \theta_{T}\right)=Q^{X}\left(X_{T}<-F_{X}, X_{S}>\bar{\omega}_{X}\right) \\
Q^{X}\left(X_{T}>F_{X}, X_{S}>\bar{\omega}_{X}, \tau_{S} \in \theta_{S}, \tau_{T} \in \theta_{T}\right)=Q^{X}\left(X_{T}>F_{X}, X_{S}<-\bar{\omega}_{X}\right)
\end{array}\right.
$$

Summing up, and expressing the conditions as the probability of $X$ being less than a constant produces the following formula.

$$
\begin{aligned}
& Q^{X}\left(X_{T}>F_{X}, X_{S}>\bar{\omega}_{X}, \tau \nless T\right) \\
= & Q^{X}\left(X_{T}<2 X_{0}-F_{X}, X_{S}<2 X_{0}-\bar{\omega}_{X}\right) \\
& -Q^{X}\left(X_{T}<-F_{X}, X_{S}<-\bar{\omega}_{X}\right) \\
& -Q^{X}\left(X_{T}<-F_{X},-X_{S}<2 X_{0}-\bar{\omega}_{X}\right) \\
& +Q^{X}\left(-X_{T}<2 X_{0}-F_{X}, X_{S}<-\bar{\omega}_{X}\right)
\end{aligned}
$$

The next step is to derive the corresponding density functions. We immediately see that the bivariate standardized cumulative functions are

$$
\begin{aligned}
& Q^{X}\left(X_{T}>F_{X}, X_{S}>\bar{\omega}_{X}, \tau_{S} \notin \theta_{S}, \tau_{T} \notin \theta_{T}\right) \\
= & \phi\left(\frac{X_{0}-F_{X}}{\sqrt{T}}, \frac{X_{0}-\bar{\omega}_{X}}{\sqrt{S}}, \sqrt{\frac{S}{T}}\right)-\phi\left(\frac{-F_{X}-X_{0}}{\sqrt{T}}, \frac{-\bar{\omega}_{X}-X_{0}}{\sqrt{S}}, \sqrt{\frac{S}{T}}\right) \\
& -\phi\left(\frac{-F_{X}-X_{0}}{\sqrt{T}}, \frac{X_{0}-\bar{\omega}_{X}}{\sqrt{S}},-\sqrt{\frac{S}{T}}\right)+\phi\left(\frac{X_{0}-F_{X}}{\sqrt{T}}, \frac{-\bar{\omega}_{X}-X_{0}}{\sqrt{S}},-\sqrt{\frac{S}{T}}\right)
\end{aligned}
$$


Keeping in mind that integration starts at $F_{X}$ and $\bar{\omega}_{X}$, respectively, and that the start value for the bankruptcy process is $X_{0}$, the density functions are

$$
\begin{aligned}
Q^{X}\left(X_{T} \in d x_{T}, X_{S} \in d x_{S}, \tau_{S} \notin \theta_{S}, \tau_{T} \notin \theta_{T}\right)= & f\left\{0, \sqrt{T} ; 0, \sqrt{S} ; \sqrt{\frac{S}{T}}\right\} d x_{T} d x_{S} \\
& -f\left\{-2 X_{0}, \sqrt{T} ;-2 X_{0}, \sqrt{S} ; \sqrt{\frac{S}{T}}\right\} d x_{T} d x_{S} \\
& -f\left\{-2 X_{0}, \sqrt{T} ; 0, \sqrt{S} ;-\sqrt{\frac{S}{T}}\right\} d x_{T} d x_{S} \\
+ & f\left\{0, \sqrt{T} ;-2 X_{0}, \sqrt{S} ;-\sqrt{\frac{S}{T}}\right\} d x_{T} d x_{S}
\end{aligned}
$$

Having derived the $Q^{X}$-density function we can return to equation (10) and integrate.

\section{B.2 Integration}

Inserting the Radon-Nikodym derivative and the derived density function into equation (10) and changing integration variables to $w_{t}$ (identical to $X_{t}$ but starting at 0 ) we obtain:

$$
\begin{aligned}
Q^{m}\left(A_{T}\right)= & e^{-\frac{1}{2}\left(h^{X \rightarrow m}\right)^{2} T} \int_{F_{X}-X_{0}}^{\infty} \int_{\bar{\omega}_{X}-X_{0}}^{\infty} \\
& \left\{\begin{array}{c}
e^{h^{X \rightarrow m} w_{T}} \times f\left\{0, \sqrt{T} ; 0, \sqrt{S} ; \sqrt{\frac{S}{T}}\right\} \\
-e^{h^{X \rightarrow m} w_{T}} \times f\left\{-2 X_{0}, \sqrt{T} ;-2 X_{0}, \sqrt{S} ; \sqrt{\frac{S}{T}}\right\} \\
-e^{h^{X \rightarrow m} w_{T}} \times f\left\{-2 X_{0}, \sqrt{T} ; 0, \sqrt{S} ;-\sqrt{\frac{S}{T}}\right\} \\
+e^{h^{X \rightarrow m} w_{T}} \times f\left\{0, \sqrt{T} ;-2 X_{0}, \sqrt{S} ;-\sqrt{\frac{S}{T}}\right\}
\end{array}\right.
\end{aligned}
$$

Completing the square yields

$$
Q^{m}\left(A_{T}\right)=e^{-\frac{1}{2}\left(h^{X \rightarrow m}\right)^{2} T} \int_{F_{X}-X_{0}}^{\infty} \int_{\bar{\omega}_{X}-X_{0}}^{\infty} f f\left\{w_{t}, w_{t}\right\} d w_{T} d w_{S}
$$


with the bivariate density function $f f\left\{w_{t}, w_{t}\right\}$ given by

$$
f f\left\{w_{t}, w_{t}\right\} \equiv\left\{\begin{array}{c}
e^{\frac{1}{2}\left(h^{X \rightarrow m}\right)^{2} T} \\
\times f\left\{h^{X \rightarrow m} T, \sqrt{T} ; h^{X \rightarrow m} S, \sqrt{S} ; \sqrt{\frac{S}{T}}\right\} \\
-\times f\left\{-2 X_{0}+h^{X \rightarrow m} T, \sqrt{T} ;-2 X_{0}+h^{X \rightarrow m} S, \sqrt{S} ; \sqrt{\frac{S}{T}}\right\} \\
-\quad \times f\left\{-2 X_{0}+h^{X \rightarrow m} T, \sqrt{T} ;-h^{X \rightarrow m} S, \sqrt{S} ;-\sqrt{\frac{S}{T}}\right\} \\
+\quad \times f\left\{h^{X \rightarrow m} T, \sqrt{T} ;-2 X_{0}-h^{X \rightarrow m} S, \sqrt{S} ;-\sqrt{\frac{S}{T}}\right\}
\end{array}\right.
$$

Cancelling terms $\left(e^{\frac{1}{2}\left(h^{X \rightarrow m}\right)^{2} T}\right.$ etc.) and integrating gives the result.

\section{Deriving Corollaries 1, 2 and 3}

\section{C.1 The conditional call}

From equation (4)

$$
\mathcal{C}_{L}\left(\omega_{t}, t ; F, T \mid \omega_{S}>\bar{\omega}\right)=e^{-r(T-t)} \cdot E^{B}\left[C_{L}\left(\omega_{T}, T ; F, T\right) \cdot I_{\left\{\omega_{S}>\bar{\omega}\right\}}\right]
$$

Since

$$
C_{L}\left(\omega_{T}, T ; F, T\right)=\left(\omega_{T}-F\right) \cdot I_{\left\{\omega_{T}>F, \tau_{S} \notin \theta_{S}, \tau_{T} \notin \theta_{T}\right\}}
$$

the expression for the conditional call can be rewritten

$\mathcal{C}_{L}\left(\omega_{t}, t ; F, T \mid \omega_{S}>\bar{\omega}\right)=e^{-r(T-t)} \cdot E^{B}\left[\left(\omega_{T}-F\right) \cdot I_{\left\{A_{T}\right\}}\right]$

$$
=e^{-r(T-t)} \cdot E^{B}\left[\omega_{T} \cdot I_{\left\{A_{T}\right\}}\right]-e^{-r(T-t)} \cdot F \cdot E^{B}\left[I_{\left\{A_{T}\right\}}\right]
$$

To separate the two terms within the expectations brackets in the first term, we change probability measure as indicated in appendix A.2:

$$
\begin{aligned}
\mathcal{C}_{L}\left(\omega_{t}, t ; F_{i}, t_{i} \mid D_{S}>K\right)= & e^{-r(T-t)} \cdot E^{B}\left[\omega_{T}\right] \cdot E^{\omega}\left[I_{\left\{A_{T}\right\}}\right] \\
& -e^{-r(T-t)} \cdot F \cdot E^{B}\left[I_{\left\{A_{T}\right\}}\right]
\end{aligned}
$$


which yields the result.

\section{C.2 The conditional heaviside}

By definition

$$
\mathcal{H}_{L}\left(\omega_{t}, t ; F, T \mid \omega_{S}>\bar{\omega}\right)=e^{-r(T-t)} \cdot E^{B}\left[H_{L}\left(\omega_{T}, T ; F, T\right) \cdot I_{\left\{\omega_{S}>\bar{\omega}\right\}}\right]
$$

Comparing the payoff to a down-and-out heaviside

$$
H_{L}\left(\omega_{T}, T ; F, T\right)=F \cdot I_{\left\{\omega_{T}>F, \tau_{S} \notin \theta_{S}, \tau_{T} \notin \theta_{T}\right\}}
$$

with (4) above, we see that a conditional heaviside is just the latter half of a conditional down-and-out call, and hence the result follows directly.

\section{C.3 The conditional dollar-in-default}

The payoff is

$$
\mathcal{G}^{L}\left(\omega_{T}, T ; T \mid \omega_{S}>\bar{\omega}, \tau_{S} \notin \theta_{S}\right) \equiv G^{L}\left(\omega_{T}, T ; T\right) \times I_{\left\{\omega_{S}>\bar{\omega}, \tau_{S} \notin \theta_{S}\right\}}
$$

i.e. the conditional dollar-in-default pays off $\$ 1$ if default occurs during $\theta_{T}$ conditional on no default during $\theta_{S}$ and $\omega_{S}>\bar{\omega}$. The value of receiving a dollar under these conditions, must be equal to receiving a long position in a (perpetual) dollar-in-default claim at $S$ conditional $\omega_{S}>\bar{\omega}$ and no default prior to $S$, less receiving a short position in a (perpetual) dollar-in-default claim at $T$ conditional $\omega_{S}>\bar{\omega}$ and no default prior to $T$. Formally

$$
\begin{aligned}
\mathcal{G}^{L}\left(\omega_{t}, t ; T \mid \omega_{S}>\bar{\omega}, \tau_{S} \notin \theta_{S}\right)= & e^{-r(S-t)} E^{B}\left[G^{L}\left(\omega_{S} ; \infty\right) \cdot I_{\left\{\bar{\omega}<\omega_{S}, \tau_{S} \notin \theta_{S}\right\}}\right] \\
& -e^{-r(T-t)} E^{B}\left[G^{L}\left(\omega_{T} ; \infty\right) \cdot I_{\left\{\bar{\omega}<\omega_{S}, \tau_{S} \notin \theta_{S}, \tau_{T} \notin \theta_{T}\right\}}\right]
\end{aligned}
$$

Using the $Q^{G}$-measure (see appendix A.1) we can separate the variables as described in appendix A.2 above:

$$
\begin{aligned}
\mathcal{G}^{L}\left(\omega_{t}, t ; T \mid \omega_{S}>\bar{\omega}, \tau_{S} \notin \theta_{S}\right)= & e^{-r(S-t)} E^{B}\left[G^{L}\left(\omega_{S} ; \infty\right)\right] E^{G}\left[I_{\left\{\bar{\omega}<\omega_{S}, \tau_{S} \notin \theta_{S}\right\}}\right] \\
& -e^{-r(T-t)} E^{B}\left[G^{L}\left(\omega_{T} ; \infty\right)\right] E^{G}\left[I_{\left\{\bar{\omega}<\omega_{S}, \tau_{S} \notin \theta_{S}, \tau_{T} \notin \theta_{T}\right\}}\right]
\end{aligned}
$$


The expected return of $G^{L}$ under the pricing measure $Q^{B}$ is $r$ and so

$$
\begin{aligned}
\mathcal{G}^{L}\left(\omega_{t}, t ; T \mid \omega_{S}>\bar{\omega}, \tau_{S} \notin \theta_{S}\right)= & G^{L}\left(\omega_{t} ; \infty\right) \cdot Q^{G}\left(\bar{\omega}<\omega_{S}, \tau_{S} \notin \theta_{S}\right) \\
& -G^{L}\left(\omega_{t} ; \infty\right) \cdot Q^{G}\left(\bar{\omega}<\omega_{S}, \tau_{S} \notin \theta_{S}, \tau_{T} \notin \theta_{T}\right)
\end{aligned}
$$

Noting that the probabilities are for events $A_{S}$ and $A_{T}$, respectively, gives the corollary. 